\title{
Welcome to Environmental Earth Sciences, formerly Environmental Geology
}

Published online: 17 July 2009

(C) Springer-Verlag 2009

Volume 59 begins publication of the journal, Environmental Earth Sciences, formerly known as Environmental Geology. While the scope and content of Environmental Geology will continue to be featured, the expanded coverage of Environmental Earth Sciences will provide the earth science community a unified vehicle for disseminating research.

Former editor, Dr. Philip LaMoreaux, worked tirelessly to improve the journal. He saw the ever-growing journal through many improvements, including establishment of an online manuscript submission and an electronic review system. He was also instrumental in soliciting an increase in manuscripts from areas of the world where reporting of research has sometimes been difficult. Under his leadership, the Editorial Board expanded in scope and discipline and the manuscripts improved in quality and comprehensiveness.

His greatest achievements are being realized today with the change in name of the journal, the expansion of its aims and scope, and the publication in full color. These were improvements that he had worked diligently to bring about and fortunately knew would come to fruition before he passed away. The new and expanded journal is a fitting tribute to his interests, reflecting all fields encompassed by the earth sciences. Over the past two decades, the journal has consistently strived to serve as a platform for peerreviewed quality research in the earth sciences.

The Editors are committed to working together to continue this tradition of service to further advance the quality and reach of the journal. Dr. Gunter Dörhöfer, who worked with Dr. Philip LaMoreaux for many years as Editor for Europe joins Dr. James LaMoreaux, who served on the Editorial Board for 9 years and as Co-Editor in Chief of Environmental Geology for the past year.

Earth sciences, in their expanse of disciplines, and often in combination with other sciences, provide valuable tools for public services. Earth scientists are constantly improving

scientific techniques and developing their usability for dealing with environmental challenges worldwide.

The practice of earth sciences historically has been cyclic by nature, rising and falling with the demand for water, minerals and energy. Today, however, as the world's population edges towards 7 billion, meeting the needs for an adequate lifestyle while lessening the environmental impact has created an increasing demand for qualified earth scientists to make informed scientific and policy decisions and responsibly implement these decisions.

To further add to the pressure, many research centers, applied earth science practitioners and government scientific agencies, find themselves impacted by the international economic cycle. If the integrity and quality of research in the traditional sciences is not carefully preserved during this difficult time, key research centers may lose their base of trained staff who are integral to their mission. If this occurs, recovery of the former scientific status can be difficult and lengthy.

To meet the needs for better methods of exchanging information and research findings while improving opportunities for those working professionally and academically in the earth sciences, the journal is implementing its extended aims and scope and new name at this time. Undoubtedly, other innovations and methods of improved information transfer will be required in the future as the discovery of the Earth's secrets continues to unfold. The Journal of Environmental Earth Sciences will continue to play an integral role in this process by providing an exchange of the best of research and ideas in the earth sciences.

Gunter Dörhöfer
Editor-in-Chief for
Europe, Africa and
West Asia

\author{
James W. LaMoreaux \\ Editor-in-Chief for \\ the Americas, Australia \\ and Eastern Asia
}

